\title{
Plant-mediated RNAi silences midgut- expressed genes in congeneric lepidopteran insects in nature
}

\author{
Spoorthi Poreddy ${ }^{1,2}$, Jiancai Li ${ }^{1}$ and Ian T. Baldwin ${ }^{1 *}$
}

\begin{abstract}
Background: Plant-mediated RNAi (PMRi) silencing of insect genes has enormous potential for crop protection, but whether it works robustly under field conditions, particularly with lepidopteran pests, remains controversial. Wild tobacco Nicotiana attenuata and cultivated tobacco (N. tabacum) (Solanaceae) is attacked by two closely related specialist herbivores Manduca sexta and M. quinquemaculata (Lepidoptera, Sphingidae). When M. sexta larvae attack transgenic N. attenuata plants expressing double-stranded RNA(dsRNA) targeting M. sexta's midgut-expressed genes, the nicotine-ingestion induced cytochrome P450 monooxygenase (invert repeat (ir)CYP6B46-plants) and the lyciumoside-IV-ingestion induced $\beta$-glucosidase1 (irBG1-plants), these larval genes which are important for the larvae's response to ingested host toxins, are strongly silenced.

Results: Here we show that the PMRi procedure also silences the homologous genes in native M. quinquemaculata larvae feeding on irCYP6B46 and irBG1-transgenic N. attenuata plants in nature. The PMRi lines shared 98 and 96\% sequence similarity with M. quinquemaculata homologous coding sequences, and CYP6B46 and BG1 transcripts were reduced by ca. 90 and 80\%, without reducing the transcripts of the larvae's most similar, potential off-target genes.

Conclusions: We conclude that the PMRi procedure can robustly and specifically silence genes in native congeneric insects that share sufficient sequence similarity and with the careful selection of targets, might protect crops from attack by congeneric-groups of insect pests.
\end{abstract}

Keywords: RNA interference, Plant-mediated RNAi, Manduca quinquemaculata, CYP6B46, $\beta$-glucosidase, Transgenic tobacco plants

\section{Background}

RNA interference (RNAi) is a sequence-specific, double stranded RNA (dsRNA) induced gene-silencing mechanism that operates at transcriptional or post-transcriptional levels and is conserved across all the eukaryotes [1], including lepidopteran insects [2]. Since the RNAi mechanism was first demonstrated in Caenorhabditis elegans in 1998, RNAi has emerged as a potent gene-silencing tool for loss-of-function analyses in a wide range of organisms $[1,3,4]$. RNAi has emerged as the most powerful technique to analyze gene function in insects, for which stable transgenesis is not available $[2,5]$. The success of RNAi in insects is highly dependent on the insect-species, target

\footnotetext{
* Correspondence: baldwin@ice.mpg.de

'Department of Molecular Ecology, Max-Planck-Institute for Chemical

Ecology, Hans-Knöll-Str. 8, D-07745 Jena, Germany

Full list of author information is available at the end of the article
}

gene and its function, organ of gene expression and mode of delivery of silencing molecules [2, 6]. RNAi-mediated gene silencing in some insect species is quite robust and can even be transmitted to subsequent generations via germ line transmission [7-9]. Coleopteran species are highly sensitive to RNAi and more efficient gene silencing can easily achievable in coleopteran insects when compared to insect species in other orders $[10,11]$. In contrast, lepidopteran species, particularly in laboratory experiments with injected dsRNA are recalcitrant to the procedure $[2,12]$.

Although the silencing of target genes in insects is achieved by various dsRNA introduction strategies, such as microinjection or oral delivery via artificial diets [13], gene silencing can be enhanced and possibly achieved under field conditions by engineering host plants to produce dsRNAs [5]. An efficient method to down-regulate 
cotton bollworm defense genes using plant-mediated RNAi (PMRi) has been described by engineering host plants to produce dsRNAs directed against bollworm larvae's P450 monooxygenase (CYP6AE14) gene in laboratory experiments [15]. Several studies have demonstrated successful gene silencing in various insect orders such as Coleoptera, Lepidotera and Hemiptera using stable or transient transgenic PMRi plants [14-21]. A recent advance in PMRi to control insects was achieved by expressing exogenous dsRNAs targeted against the $\beta$-actin gene of the Colorado potato beetle $(\mathrm{CPB})$ via chloroplast transformation in potato. Transplastomic potato plants were shown to be lethal to $\mathrm{CPB}$ larvae and were protected from $\mathrm{CPB}$ attack in glasshouse experiments [22].

The capacity of insect pests to adapt to conventional insecticides [23] or to Bacillus thuringiensis (Bt) expressing plants [24] is an ongoing concern for the long-term pest management of crop plants. The PMRi approach offers the potential to develop insect-resistant crops that produce insecticidal dsRNAs, but only a few reports have demonstrated its potential under field conditions $[17,20,25,26]$. Crop plants are commonly attacked by congeneric insect pests, for instance Spodoptera litura and S. exigua are both major pests of various crops [27]; Helicoverpa armigera and $H$. punctigera are major pests of cotton [28]; H. armigera and $H$. zea attack maize plants [29]. Hence whether PMRi can silence conserved essential genes in congeneric insect pests under field condition would be an important test of this procedures utility as a crop protection tool.

The congeneric species, tobacco hornworm [Manduca sexta (Ms), Linnaeus, 1763] and tomato hornworm [M. quinquemaculata $(M q)$, Haworth, 1803] (Lepidoptera: Sphingidae) are closely related sympatric sibling species [30-32] that both attack solanaceous crops in North America [33]. These two insects have similar morphologies [34], behavior [35], and ecology [36] and their hostplant interactions have been intensely studied [31, 37-39]. Both of these hornworm species are significant pests on solanaceous crops in North America. In nature, the annual tobacco plant Nicotiana attenuata Torr. ex Wats, native to Great Basin Desert of southwestern Utah is a common host plant for both of these pest insects and both also attack cultivated tobacco.

Recently, we elucidated $M$. sexta's counter-adaptation strategies against two of $N$. attenuata's major chemical defenses, namely nicotine and 17-hydroxygeranyllinalool diterpene glycosides (HGL-DTGs), by silencing $M$. sexta's midgut-expressed cytochrome P450 monooxygenase (CYP6B46) and $\beta$-glucosidase1 (BG1) genes. This was accomplished by developing transgenic $N$. attenuata PMRi lines that expressed inverted repeat (ir) constructs of CYP6B46 and BG1 and planting these irCYP6B46 and
irBG1 plants into field plots in the plants and insects native habitat $[25,26]$. Since $M$. sexta and $M$. quinquemaculata are closely related, co-occurring species in $N$. attenuata's native habitat [40], we hypothesized that PMRi plants producing $M$. sexta's CYP6B46 and BG1 dsRNA could silence the homologous genes in native $M$. quinquemaculata.

\section{Results}

\section{Experimental system used to evaluate homologous gene} silencing

$M$. sexta and $M$. quinquemaculata are two specialist herbivores of $N$. attenuata (Fig. 1a). Previously, we silenced the expression of $C Y P 6 B 46$ and $B G 1$ in $M$. sexta larval midguts using PMRi lines irCYP6B46 [25] and irBG1 [26], respectively. These stable transgenic irCYP6B46 and irBG1 $N$. attenuata lines were generated using Agrobacterium tumefaciens-mediated transformation with an inverted repeat of 312 and $301 \mathrm{bp}$ $M s$ CYP6B46 and MsBG1 complementary DNA (cDNA), respectively. Here, we utilized these PMRi plants generated from $M$. sexta genes to examine the silencing of the homologous genes in a wild population of M. quinquemaculata (Fig. 1b).

\section{M. sexta CYP6B46 and BG1 genes share high sequence similarity with $M$. quinquemaculata homologous genes} Since PMRi operates in a sequence specific manner to silence target gene transcripts, homologous gene silencing depends on sequence similarities between homologous genes particularly in the regions that are used in the generation of the transgenic plants. To test the sequence similarities of $M s \mathrm{CYP} 6 \mathrm{~B} 46$ and $M s \mathrm{BG} 1$ with their corresponding homologous genes in M. quinquemaculata, we aligned the partial coding sequences of MsCYP6B46 (312 bp) and MsBG1 (301 bp) used in the generation of the irCY6B46 and irBG1 PMRi plants with the coding regions of $M$. quinquemaculata's homologous genes. We found that the M. sexta CYP6B46 fragment cloned to generate the irCYP6B46 plants shared 98\% sequence similarity with the $M$. quinquemaculata CYP6B46 sequence (Fig. 2a) and that the M. sexta BG1 fragment cloned to generate the irBG1 plants shared 96\% sequence similarity with the $M$. quinquemaculata BG1 sequence (Fig. 2b). Notably, five identical homologous regions of $>21 \mathrm{nt}$ were identified in the alignment of $M s C Y P 6 B 46$ and $M q C Y P 6 B 46$. The lengths of these identical regions were $25 \mathrm{nt}(+19$ to 43$), 42 \mathrm{nt}(+61$ to 102), $49 \mathrm{nt}(+104$ to 152$), 62 \mathrm{nt}(+154$ to 215$), 62 \mathrm{nt}(+217$ to 278), 33 nt (+280 to 312) (Fig. 2a). Three identical homologous regions of $>21 \mathrm{nt}$ were identified in the alignment of MsBG1 and MqBG1. The lengths of these identical regions were $55 \mathrm{nt}$ ( +55 to 109$), 80 \mathrm{nt}(+129$ to 208), 44 nt (+222 to 265) (Fig. 2b). 


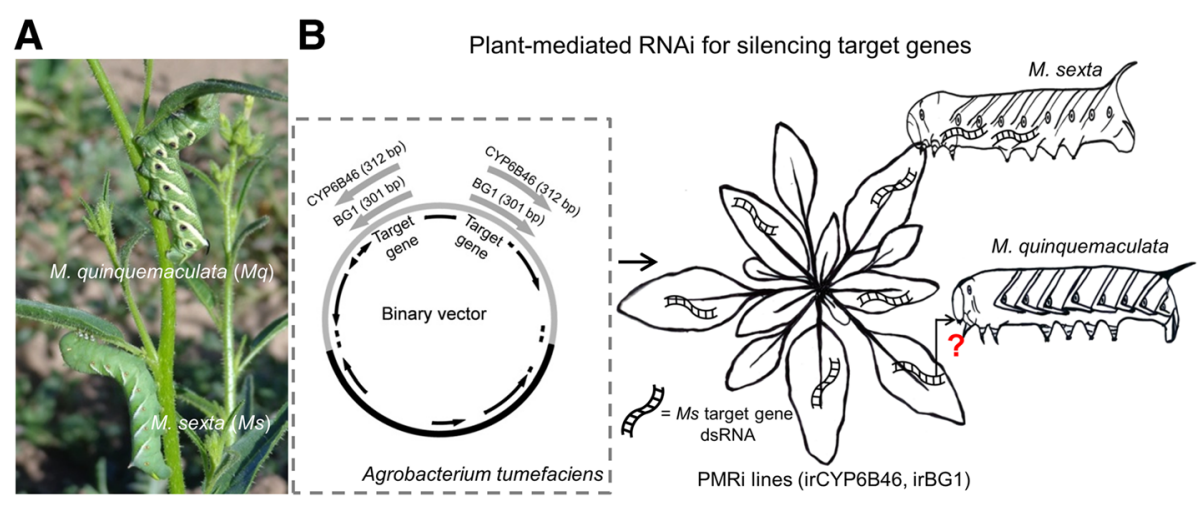

Fig. 1 Experimental system used to evaluate if the PMRi lines generated from Manduca sexta genes can silence M. quinquemaculata homologous genes. a Fifth-instar M. sexta and its closely related species M. quinquemaculata larvae on their native host plant, the wild tobacco Nicotiana attenuata in Great Basin Desert of southwestern Utah. $\mathbf{b}$ Schematic overview of plant-mediated RNAi: the binary vector constructed to independently express $\sim 300$ bp dsRNA of M. sexta's target genes such as cytochrome P450 monooxygenase (CYP6B46) and $\beta$-glucosidasel (BG1) in N. attenuata. The trophic transfer of these dsRNA from plant to $M$. sexta larvae silences their respective target gene expression. PMRi lines generated with $M$. sexta dsRNA were used to test if the trophic transfer can also silence homologous gene expression in M. quinquemaculata larvae in nature

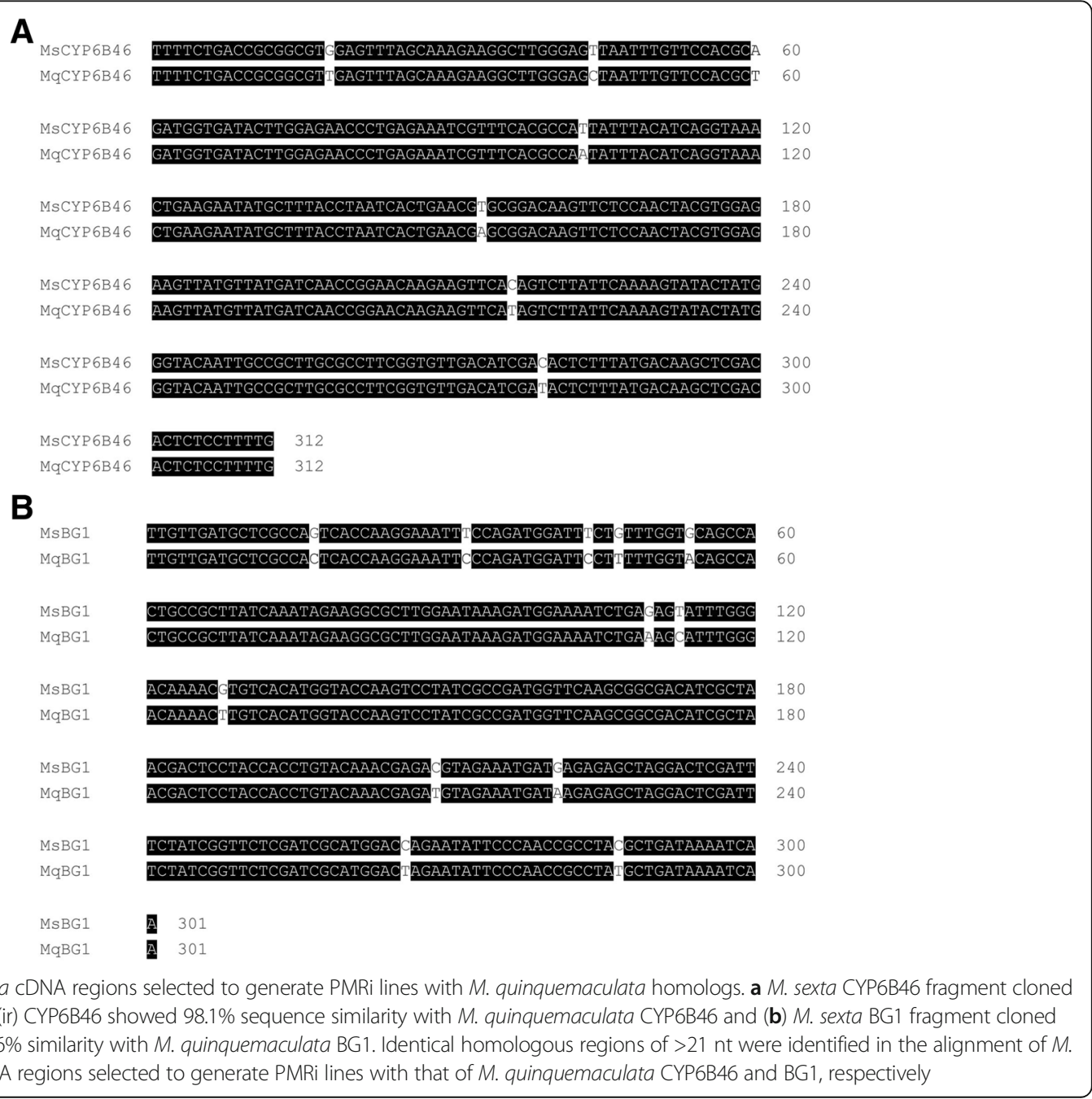


Silencing of CYP6B46 and BG1 in wild M. quinquemaculata Naturally oviposited wild Manduca spp. eggs (Fig. 3a) were collected from the study area and larvae were reared on empty vector (EV), inverted repeat putrescine $N$-methyl transferase (irPMT), inverted repeat geranylgeranyl pyrophosphate synthase (irGGPPS), irCYPB46 and irBG1 $N$. attenuata plants (Table 1) that were planted in a field plot located in $N$. attenuata's native habitat (Fig. 3b), until they had reached the fourthinstar. The two species are easily distinguished when they attain the third-instar. In M. sexta larvae CYP6B46 and BG1 are the midgut-expressed genes that are induced in response to the ingestion of nicotine and lyciumoside IV (a major HGL-DTG), respectively. To test whether these candidate genes were midgut expressed in M. quinquemaculata, and are induced by the ingestion of nicotine and lyciumoside IV, we profiled their transcript levels in various tissues, including foregut, midgut, hindgut, hemolymph, Malpighian tubules and fat body along with skin, in nicotine and lyciumoside

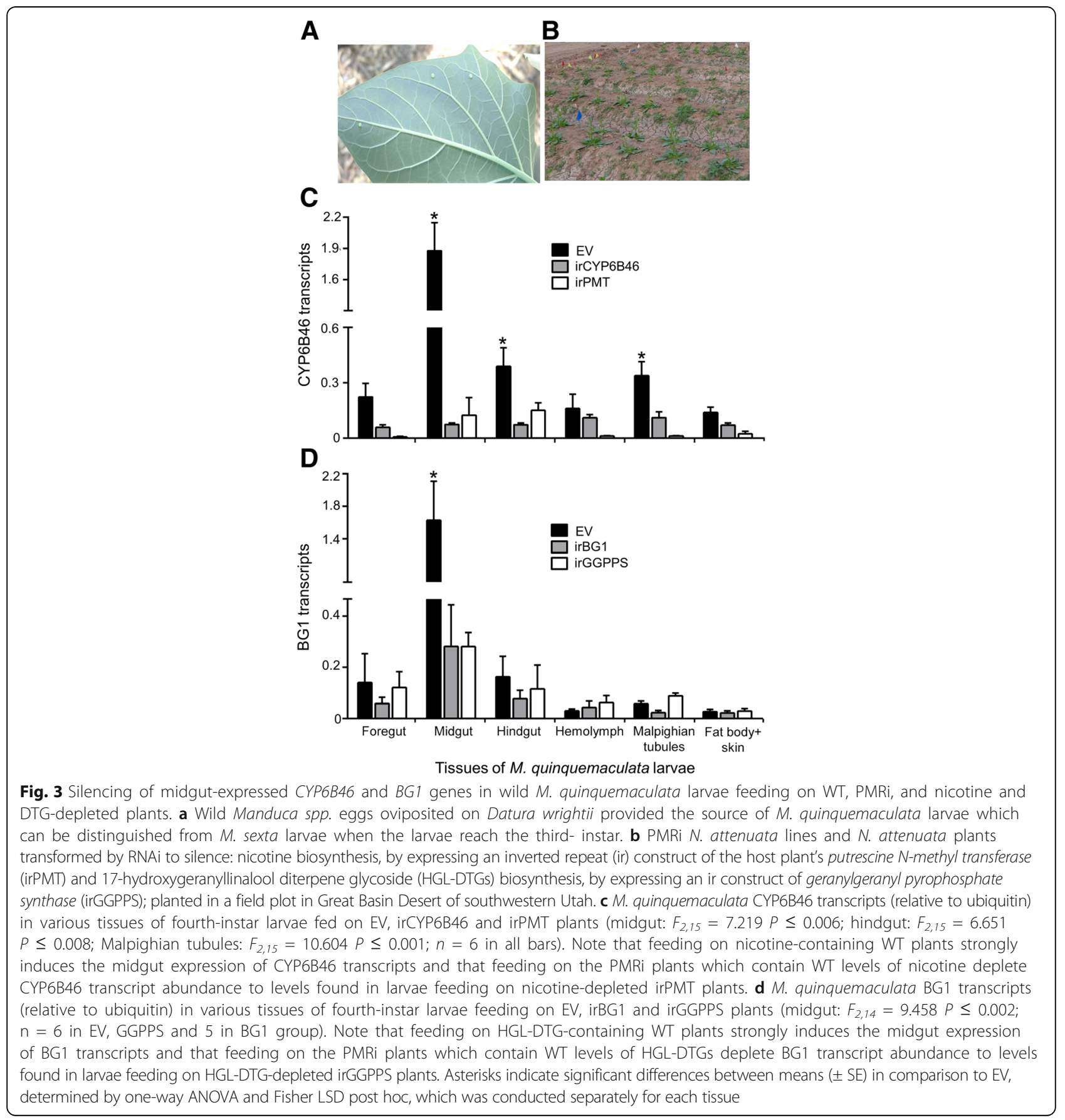


Table 1 APHIS notification numbers for importing seeds and releasing transgenic $N$. attenuata plants

\begin{tabular}{llll}
\hline Line & Import \# & Year & Release \# \\
\hline EV & $07-341-101 \mathrm{n}$ & 2014 & $13-350-101 \mathrm{r}$ \\
$\begin{array}{l}\text { irPMT (NaPMT NCBI } \\
\text { accession no. AF280402) }\end{array}$ & $07-341-101 \mathrm{n}$ & 2014 & $13-350-101 \mathrm{r}$ \\
irGGPPS (NaGGPPS NCBI & $07-341-101 \mathrm{n}$ & 2014 & $13-350-101 \mathrm{r}$ \\
$\begin{array}{l}\text { accession no. EF382626) } \\
\text { irCYP6B46 (MsCYP6B46 }\end{array}$ & $10-004-105 \mathrm{~m}$ & 2014 & $13-350-101 \mathrm{r}$ \\
$\begin{array}{l}\text { NCBI accession no. GU731529) } \\
\text { irBG1 (MsBG1 NCBI }\end{array}$ & $10-004-105 \mathrm{~m}$ & 2014 & $13-350-101 \mathrm{r}$ \\
accession no. FK816842) & & & \\
\hline
\end{tabular}

IV containing EV-fed control, nicotine depleted irPMTfed, and lyciumoside IV depleted irGGPPS-fed larvae. Both the genes, namely CYP6B46 ( $P \leq 0.001$; Fig. 3c) and BG1 $(\mathrm{P} \leq 0.001 ; 3 \mathrm{D})$ were found to have relatively higher expression levels in the midguts of larvae feeding on EV plants than in the larvae feeding on irPMT and irGGPPS plants, respectively suggesting that feeding on nicotine- and lyciumoside IV-containing EV plants strongly induced the midgut expression of CYP6B46 and BG1 transcripts. Although the transcript abundance of CYP6B46 was higher $(P \leq 0.005$; Fig. $3 c)$ in hindguts and Malpighian tubules of larvae feeding on EV plants than in the larvae feeding on irPMT plants, the CYP6B46 expression in these tissues is significantly lower (six-fold) as compared to that of midguts.

Midguts of irCYP6B46-fed larvae showed $>90 \%$ lower abundance of CYP6B46 transcripts than that of EV-fed larvae. Feeding on the irCYP6B46 PMRi plants which contain nicotine levels similar to those of $\mathrm{EV}$ plants reduced the CYP6B46 transcript levels to that found in larvae feeding on nicotine-depleted irPMT plants (Fig. 3c; $F_{2,15}=7.219 P \leq 0.006$ ). Transcript abundance of BG1 in the midguts of irBG1-fed larvae was $>80 \%$ lower than that of EV-fed larvae and the reduction in BG1 transcripts was not observed in other tissues of irBG1-fed larvae. Feeding on the irBG1 PMRi plants which contain HGL-DTGs similar to those of EV plants reduced the BG1 transcript abundance to levels found in larvae feeding on HGLDTG-depleted irGGPPS plants (Fig. 3d; $F_{2,14}=9.458$ $P \leq 0.002$ ).

\section{Sequence analysis of MqCYP6B46 and MqBG1 with their potential off-target genes}

Gene silencing may also result in silencing of non-target genes that belong to closely related gene families if they share high sequence similarities in the targeted regions. Off-target effects could be minimized by using a region of coding sequence for inverted repeat construct preparation which is specific to the targeted gene and do not share high sequence similarity with other closely related genes. Sequence similarities of $M q$ CYP6B46 and MqBG1 coding sequences with their corresponding potential off target genes $M q \mathrm{CYP} 6 \mathrm{~B} 45$ and $M q \mathrm{BG} 2$, respectively were determined by aligning their coding regions. $M q$ CYP6B46 partial coding sequence had $82 \%$ sequence similarity to MqCYP6B45 and one identical homologous region with a continuous stretch $>21$ nt (Fig. 4a). The MqBG1 partial coding sequence shared $71 \%$ sequence similarity with $M q B G 2$ and no identical homologous regions with a continuous stretch $>21$ nt (Fig. 4b). MqCYP6B46 and MqBG1 sequences didn't show sequence similarity $>21 \mathrm{nt}$ with the sequences of other non-target organisms that are available in NCBI database.

\section{Silencing of MqCYP6B46 and MqBG1 is target gene specific}

To determine whether silencing of MqCYP6B46 and $M q B G 1$ was target-gene specific, we quantified the transcript levels of $M q \mathrm{CYP} 6 \mathrm{~B} 45$ and $M q \mathrm{BG} 2$, respectively. CYP6B45 transcript levels in the midguts of larvae feeding on irCYP6B46 were as not reduced in comparison to those of EV-fed larvae (Fig. 4c). From these results, we infer that the one identical continuous stretch $>21 \mathrm{nt}$ was not used in the production of potential small interfering RNA or that the silencing signal was not sufficient to reduce CYP6B45 transcript levels. Transcript abundance of BG2 in the midguts of larvae feeding on irBG1 plants was also not reduced and even slightly higher than those of EV-fed larvae (Fig. 4d). These results suggest that $M q \mathrm{CY} 6 \mathrm{~B} 46$ and $M q \mathrm{BG} 1$ silencing by PMRi was highly sequence-specific and free of off-target effects.

\section{Discussion}

Silencing of insect genes in congeneric species in their native habitat by in planta expression of insecticidal dsRNAs holds a great promise for the future development of broad spectrum insect resistant crop plants [41, 42]. Previously, we showed that plant-mediated RNAi is highly efficient in silencing $M$. sexta genes in its natural environment $[25,26]$. In this study, we showed that the homologous target genes in the midgut of the lepidopteran $M$. quinquemaculata can be suppressed by feeding native $M$. quinquemaculata larvae on transgenic $N$. attenuata plants producing dsRNA against $M$. sexta midgut-expressed genes, under field conditions. Although we did not collect the precise data on larval life cycle parameters and defoliation rates while feeding on transgenic plants, we did not observe any noticeable differences in larval mass and plant defoliation rates between those feeding on control (EV) and transgenic RNAi lines (irCYP6B46 and irBG1).

The RNAi-induced silencing in insects is initially achieved majorly via three dsRNA-delivery methods, such as injection [43], ingestion [14] and feeding dsRNA producing bacteria [44]. These delivery methods were 
A

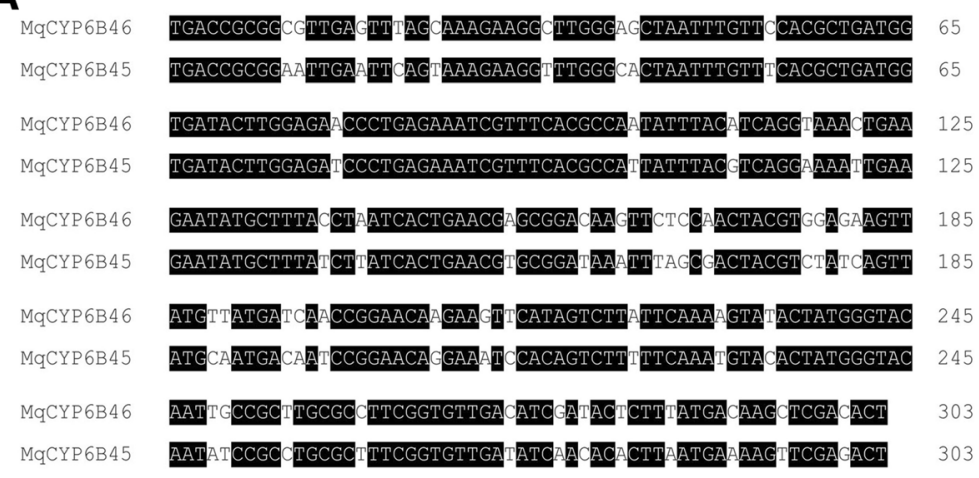

B

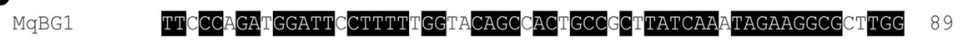

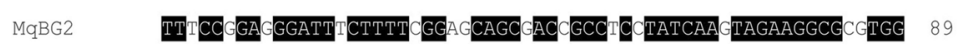

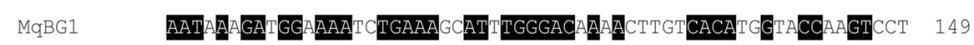

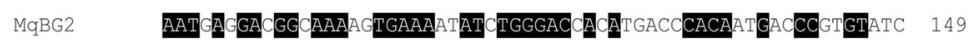

MqBG1 ATCGCCGATGGTCAMGGGGGACATCGC TAACGACTCCTACCACCT GTACAAACGAGA 209

MqBG2 ATCAAAGACTGTTCG IATGGTGACATCGCCGCCGACTCCTACCACAA GTACCAACGCGAC 209

MqBG1 GTAGAAATGATAAGAACCTAGGACTCGATTTCTA CGGTTCTCGAT 256

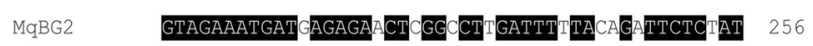

C

D

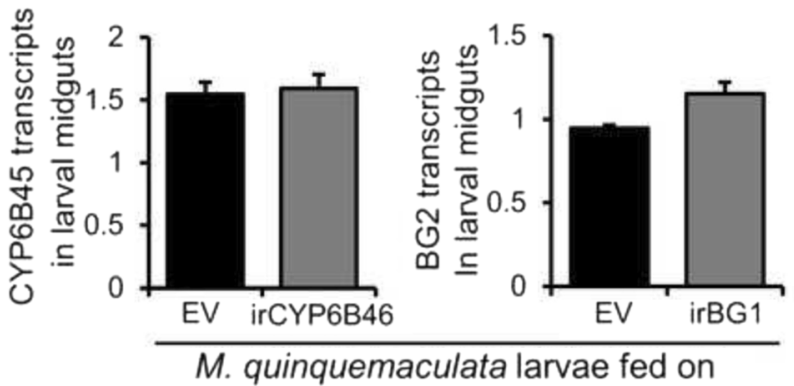

Fig. 4 Silencing of MaCYP6B46 and MaBG1does not silence the most closely related, likely non-target genes. a Alignment of MqCYP6B46 partial coding sequence with MqCYP6B45 showed 83\% sequence similarity and one identical homologous region $>21$ nt was identified. b Alignment of MaBG1 coding sequence with MqBG2 showed 71\% sequence similarity and no identical homologous regions $>21$ nt were identified. Transcripts (relative to ubiquitin) of (c) MqCYP6B45 and (d) MaBG2 in the midguts of fourth-instar EV-, irCYP6B46 and EV-, irBG1-feeding larvae did not show off-target silencing of CYP6B45 and BG2, respectively, $(n=6)$ Significant differences between means $( \pm S E)$ in comparison to EV was determined by one-way ANOVA and Fisher LSD post hoc test

not efficient in silencing of target genes in lepidoteran insects perhaps due to the instability of dsRNAs upon exposure to the nuclease rich environment of the larval gut $[17,19,45]$. However, the following reports successfully demonstrated gene silencing in $M$. sexta, firstly the integrin-beta1 gene silencing is achieved by injection of dsRNAs. The integrin-betal gene is required for haemocytic encapsulation and its silencing decreased the encapsulation of haemocytes [46]. In the other study, silencing of $M$. sexta nitric oxide synthase was reported [47]. RNAi-induced silencing in larval chemosensory tissues was achieved by Howlett and colleagues by feeding dsRNA targeting a chemosensory receptor gene in $M$. sexta [48].

In addition to the abovementioned successful RNAiinduced silencing studies in $M$. sexta, Terenius and colleagues have also reported the variable sensitivity of $M$. sexta larvae to RNAi techniques, particularly when dsRNA is delivered by injection [2]. The efficiency of target gene silencing may be enhanced by the continuous supply of dsRNA, because the core RNAi genes in $M$. sexta larvae are known to be induced in response to the dsRNA injection and elevated when contact with exogenous dsRNA is prolonged [12]. Injected dsRNA into 
M. sexta hemolymph is unstable and rapidly degraded by RNAse [49].

The PMRi approach, in which the insect's host plant is utilized as an oral delivery vehicle of dsRNAs could circumvent the problem of dsRNA degradation by continuously supplying dsRNA to feeding larvae $[14,16] . M$. sexta midgut-expressed, nicotine-ingestion induced CYP4B46, CYP4M1 and CYP4M3 genes are efficiently silenced without any co-silencing of closely related non target genes, using plant virus based dsRNA-producing system (VDPS) [19]. VDPS based target gene silencing is rapid and does not require the laborious generation of stable transgenic plants; however, this method is transient and cannot yet be used under field conditions. Whereas, silencing of $M$. sexta midgut genes CYP6B46 [25] and $B G 1$ [26] was achieved under field conditions using PMRi approach and revealed the role of CYP6B46 and $B G 1$ in $M$. sexta's counter-adaptation strategies against $N$. attenuata's defense metabolites nicotine and lyciumoside IV. Yet, the application of PMRi has certain limitations, mainly off-target effects [50], silencing of the genes in non-targeted organisms in the field conditions. The off-target effects can be circumvented by careful selection of target pest gene sequences and performing thorough bioinformatics analysis to determine whether they share potential sequence similarity with the homologous genes in the other organisms [41, 50,51]. On the other hand, PMRi approach is a potential tool for silencing the target genes in the congeneric pest species if they share sufficient sequence similarity as showed in the present study.

\section{Conclusions}

We showed that PMRi transgenic plants generated with $M$. sexta genes silences the CYP6B46 and BG1 homologous genes in native $M$. quinquemaculata. The PMRi lines shared 98 and $96 \%$ sequence similarity with $M$. quinquemaculata homologous coding sequences, and CYP6B46 and BG1 transcripts were reduced by ca. 90 and $80 \%$, without any off-target effects. We conclude that the PMRi procedure can robustly and specifically silence genes in congeneric insects that share sufficient sequence similarity for the targeted genes when feeding on transformed plants growing in the rough and tumble of nature. An important implication of the work is that with the careful selection of targets, the PMRi procedure might be used to protect crops from attack by congeneric groups of insect pests.

\section{Methods}

\section{Plant material}

All the stable transgenic $N$. attenuata lines EV [52], irPMT [53], irGGPPS [54], irCYP6B46 [19] and irBG1 [26] used in the study were previously characterized. irPMT $N$. attenuata plants (A-03-108-3) were used as nicotine deficient host plants, irGGPPS $N$. attenuata plants (A-07230-5) were used as HGL-DTG depleted host plants, irCYP6B46 transgenic $N$. attenuata PMRi plants (A-0930-2) were used to silence $M$. quinquemaculata CYP6B46, irBG1 transgenic $N$. attenuata PMRi plants (A-08-375-10) were used to silence $M$. quinquemaculata $\mathrm{BG1}$ and EV-transformed plants (A-04-266-3) were used as transgenic controls. Silencing of M. sexta CYP6B46 and BG1 using irCYP6B46 and irBG1 PMRi plants, respectively was reported previously $[25,26]$.

These transgenic lines were developed from $N$. attenuata 30x inbred seeds, which was originally collected in 1988 from a native population in Utah (USA) [55]. Field experiments were conducted at the Lytle Ranch Preserve in

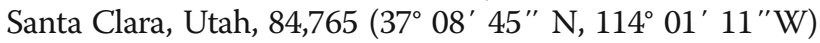
in 2014. Seeds of $N$. attenuata EV, irPMT, irGGPPS, irCYP6B46 and irBG1 lines were imported and released in accordance with Animal and Plant Health Inspection Service notifications (Table 1). Seedlings of $N$. attenuata were transferred to $50 \mathrm{~mm}$ peat pellets (Jiffy) 15 days after germination, then seedlings were kept in the shade to get acclimatized to the environmental conditions of high sunlight and low relative humidity over 14 days. Adapted early rosette-stage plants were transplanted in to the field plot and plants were watered regularly until roots were established.

\section{M. quinquemaculata}

Wild Manduca spp. eggs were collected from natural ovipositions on native $N$. attenuata and Datura populations in the study area during May 2014. The hatched neonates were transferred to rosette-stage $N$. attenuata plants and reared until they had reached the third instar when the two species, the tobacco hornworm (M. sexta) and the tomato hornworm (M. quinquemaculata) can be morphologically distinguished. When the $M$. quinquemaculata larvae had reached the fourth-instar they were used in all the experiments.

\section{Harvesting larval tissues}

Fourth-instar M. quinquemaculata larval tissues such as foregut, midgut, hindgut, hemolymph, Malpighian tubules and fat body along with skin were collected in RNA-later for transcript profiling of target and off-target genes. Larvae were immobilized by placing them on ice before dissection. First, haemolymph was collected by clipping the larval horn, as previously described [19]. Then, larvae were dissected to collect various tissues. Gut content and peritrophic membrane was removed before midgut collection. Dissected tissues were immediately transferred to RNA-later solution (Ambion) and stored at $-80{ }^{\circ} \mathrm{C}$ as recommended by the manufacturer, until further use. 
Total RNA isolation and CDNA synthesis

Tissues stored in RNA later solution were recovered and total RNA was extracted using TRI reagent (Invitrogen) according to manufacturer's protocol. The integrity and purity of extracted RNA was monitored by denaturing agarose gel electrophoresis and nanodrop spectrophotometer. Isolated total RNA was subjected to TURBO DNase (Ambion) treatment to remove genomic DNA contamination. For each sample, $500 \mathrm{ng}$ of total RNA was used for cDNA synthesis using oligo(dT)18 primer and SuperScript II enzyme (Invitrogen) according to manufacturer's instructions.

\section{Sequencing of partial coding regions}

M. quinquemaculata Ubiquitin, CYP6B46, CYP6B45, $B G 1$ and $B G 2$ gene sequences were initially retrieved from $M$. quinquemaculata midgut transcriptome and partial coding sequences of all these genes were sequenced by Sanger dideoxy sequencing method. The obtained partial coding sequences of Ubiquitin, CYP6B46, CYP6B45, BG1 and BG2 were submitted to NCBI under the accession numbers KX074011, KX074015, KX074014, KX074013 and KX074012, respectively. The primer sequences used for amplification of partial coding sequences were listed in Table 2.

\section{Real time quantitative PCR}

Transcript levels of Ubiquitin, CYP6B46, CYP6B45, BG1 and $B G 2$ were determined by $\mathrm{qRT}-\mathrm{PCR}$ conducted in Mx3005P Multiplex qPCR system (Stratagene) using qRT-PCR SYBR Green I kit (Eurogentec). All the primer pairs (Table 2) used in qRT-PCR were designed using Primer3 software version 4.0 (http://primer3.ut.ee/ ) and were commercially synthesized (Sigma-Aldrich). The PCR reactions were performed in final volume of $10 \mu \mathrm{l}$ containing the $2 \times$ qRT-PCR SYBR Green master mix (Eurogentec), $1 \mu \mathrm{l}$ of primers $(5 \mu \mathrm{M})$ and $4 \mu \mathrm{l}$ of ten times diluted synthesized cDNA. Standard dilutions of pooled cDNA from at least five biological replicates were used for external standards. The following conditions were used for qPCR: initial denaturation step at $95{ }^{\circ} \mathrm{C}$ for 30s, followed by 40 cycles of amplification at $95{ }^{\circ} \mathrm{C}$ for $30 \mathrm{~s}$ and $60{ }^{\circ} \mathrm{C}$ for $1 \mathrm{~min}$, with a final extension step of $95{ }^{\circ} \mathrm{C}$ for 30s. To check the specificity of reactions, melt curve analysis was performed at $60-95{ }^{\circ} \mathrm{C}$ after 40 cycles and the PCR efficiency of each gene was tested (Additional file 1: Table S1). Relative quantification of transcripts was carried out by the comparative D cycle threshold method using external standard curves as previously standardized $[19,56]$. MqUbiquitin levels were used as internal controls to normalize the transcript levels of target genes.

Table $2 M$. quinquemaculata gene primers used in various experiments

\begin{tabular}{|c|c|c|c|}
\hline No & Gene & Primer sequences $\left(5^{\prime}-3^{\prime}\right)$ & Use \\
\hline \multirow[t]{2}{*}{1} & \multirow[t]{2}{*}{ MqUbiquitin } & For- CAAGAAGCGCAAGAAGAAGAAC & \multirow[t]{2}{*}{ Internal control for M. quinquemaculata transcript quantification } \\
\hline & & Rev- CGTCCACCTTGTAGAACCTAAG & \\
\hline \multirow[t]{2}{*}{2} & \multirow[t]{2}{*}{ MqBG1 } & For- CCAACCGCCTATGCTGATAAA & \multirow{2}{*}{$\begin{array}{l}\text { Transcript quantification and testing the silencing } \\
\text { efficiency of } M \text {. quinquemaculata BG } 1\end{array}$} \\
\hline & & Rev- GTGACCATGGGTTGGATGTT & \\
\hline \multirow[t]{2}{*}{3} & \multirow[t]{2}{*}{ MqBG2 } & For- GCTGTATGTTACGGCCAAGA & \multirow{2}{*}{$\begin{array}{l}\text { Transcript quantification and testing the co-silencing } \\
\text { efficiency of } M \text {. quinquemaculata } B G 2\end{array}$} \\
\hline & & Rev- CACGCGCCTTCTACTTGATA & \\
\hline \multirow[t]{2}{*}{4} & \multirow[t]{2}{*}{ MqCYP6B46 } & For- GTGCCTATTACTCCGCGATCTA & \multirow{2}{*}{$\begin{array}{l}\text { Transcript quantification and testing the silencing } \\
\text { efficiency of M. quinquemaculata CYP6B46 }\end{array}$} \\
\hline & & Rev- CAAGCCTTCTITGCTAAACTCC & \\
\hline \multirow[t]{2}{*}{5} & \multirow[t]{2}{*}{ MaCYP6B45 } & For- GAAATGGATAAATTGGTTTTGACC & \multirow{2}{*}{$\begin{array}{l}\text { Transcript quantification and testing the co-silencing } \\
\text { efficiency of } M \text {. quinquemaculata CYP6B45 }\end{array}$} \\
\hline & & Rev- TTATTITGACAGAGAAGATTGAGG & \\
\hline \multirow[t]{2}{*}{6} & \multirow[t]{2}{*}{ MqUbiquitin } & For- CGACTACAACATCCAGAAGGAG & \multirow{2}{*}{$\begin{array}{l}\text { Amplification of partial coding sequence of } \\
\text { M. quinquemaculata Ubiquitin }\end{array}$} \\
\hline & & Rev- GGCTTACGGCTACATCTTAGTC & \\
\hline \multirow[t]{2}{*}{7} & \multirow[t]{2}{*}{ MqBG1 } & For- GAAGTTGTTGATGCTCGCC & \multirow{2}{*}{$\begin{array}{l}\text { Amplification of partial coding sequence of } \\
\text { M. quinquemaculata } B G 1\end{array}$} \\
\hline & & Rev- GTGACCATGGGTTGGATG & \\
\hline \multirow[t]{2}{*}{8} & \multirow[t]{2}{*}{$M q B G 2$} & For- GCTGTATGTTACGGCCAAG & \multirow{2}{*}{$\begin{array}{l}\text { Amplification of partial coding sequence of } \\
\text { M. quinquemaculata } B G 2\end{array}$} \\
\hline & & Rev- GGCTGAATATTGTATTTAAGC & \\
\hline \multirow[t]{2}{*}{9} & \multirow[t]{2}{*}{ MqCYP6B46 } & For- TGCCTATTACTCCGCGATCTA & \multirow{2}{*}{$\begin{array}{l}\text { Amplification of partial coding sequence of } \\
\text { M. quinquemaculata CYP6B46 }\end{array}$} \\
\hline & & Rev- TCAATTCGCTTGCGTAGGT & \\
\hline \multirow[t]{2}{*}{10} & \multirow[t]{2}{*}{ MqCYP6B45 } & For- GATCAAAGATTTCGACGTGTTCAT & \multirow{2}{*}{$\begin{array}{l}\text { Amplification of partial coding sequence of } \\
\text { M. quinquemaculata CYP6B45 }\end{array}$} \\
\hline & & Rev- ACTTTGAGAGGGAAGATTGAAA & \\
\hline
\end{tabular}




\section{Sequence similarity}

M. sexta's CYP6B46 and BG1 coding sequences used to generate PMRi lines with corresponding homologous coding sequences of $M$. quinquemaculata were aligned and sequence similarities were determined using nucleotide BLAST (www.ncbi.nlm.nih.gov). Aligned regions were scrutinized for continuous stretches $>21$ nt. In a similar way, MqCYP6B46 and MqBG1 partial coding sequences were aligned with potential off-target genes to determine their sequence similarity.

\section{Statistical analysis}

All statistical analyses were performed with StatView version 5 (SAS Institute Inc.). All transcript levels were analyzed by one-way analysis of variance and the statistical significance $(P \leq 0.05)$ was determined by Fisher's least significant difference post hoc tests.

\section{Additional file}

Additional file 1: Table S1. Name, accession number, slope, efficiency and $R^{2}$ of Mq target genes. (DOCX $13 \mathrm{~kb}$ )

\section{Abbreviations}

BG1: $\beta$-glucosidase1; Bt: Bacillus thuringiensis; CPB: Colorado potato beetle; CYPs: Cytochrome P450 monooxygenases; dsRNA: double-stranded RNA; EV: Empty vector;

HGL-DTG: 17-hydroxygeranyllinalool diterpene glycosides; ir: inverted repeat; irGGPPS: inverted repeat geranylgeranyl pyrophosphate synthase; irPMT: inverted repeat putrescine N-methyl transferase; Mq: Manduca quinquemaculata; Ms.: Manduca sexta; PMRi: Plant-mediated RNA interference; RNAi: RNA interference

\section{Acknowledgements}

We thank Brigham Young University for use of their Lytle Ranch Preserve field station, and Danny Kessler, Celia Diezel and Pia Backmann for support with the field experiments, and all Utah folks of field season 2014 for their assistance in collecting wild Manduca spp. eggs, and Sagar Pandit and Shuquing $x u$ for sharing M. quinquemaculata midgut transcriptome, and Mariana Stanton and Sagar Pandit for the scientific discussions, and Klaus Gase and Thomas Hahn for assistance with molecular work.

\section{Funding}

This work was supported by the Max Plank Society and the Collaborative Research Centre ChemBioSys (CRC 1127 ChemBioSys) which is funded by the Deutsche Forschungsgemeinschaft (DFG).

\section{Availability of data and materials}

All data generated or analyzed during this study are included in this article. The transgenic plants used in the current study are available from the corresponding author on reasonable request. Sequence data from this study can be found in NCBI's GenBank data library (https://www.ncbi.nlm.nih.gov/) under accession numbers listed in methods section.

\section{Authors' contributions}

SP designed and performed the experiments, analyzed the data, and wrote the manuscript. JL performed the experiments and ITB supervised the study and revised the manuscript. All authors read and approved the final manuscript.

\section{Ethics approval and consent to participate}

Not applicable

\section{Consent for publication}

Not applicable

\section{Competing interests}

The authors declare that they have no competing interests.

\section{Publisher's Note}

Springer Nature remains neutral with regard to jurisdictional claims in published maps and institutional affiliations.

\section{Author details}

${ }^{1}$ Department of Molecular Ecology, Max-Planck-Institute for Chemical Ecology, Hans-Knöll-Str. 8, D-07745 Jena, Germany. ${ }^{2}$ Present address: Department of Plant and Microbial Biology, University of Zurich, Zollikerstrasse 107, CH-8008 Zurich, Switzerland.

Received: 19 April 2017 Accepted: 2 November 2017

Published online: 13 November 2017

\section{References}

1. Fire A, Xu S, Montgomery MK, Kostas SA, Driver SE, Mello CC. Potent and specific genetic interference by double-stranded RNA in Caenorhabditis elegans. Nature. 1998;391(6669):806-11.

2. Terenius O, Papanicolaou A, Garbutt JS, Eleftherianos I, Huvenne H, Kanginakudru S, Albrechtsen M, An C, Aymeric JL, Barthel A, et al. RNA interference in Lepidoptera: an overview of successful and unsuccessful studies and implications for experimental design. J Insect Physiol. 2011; 57(2):231-45.

3. Kalleda N, Naorem A, Manchikatla RV. Targeting fungal genes by diced siRNAs: a rapid tool to decipher gene function in Aspergillus nidulans. PLoS One. 2013;8(10):e75443.

4. Liuqi G, Douglas CK. Recent advances in RNA interference research in insects: Implications for future insect pest management strategies. Crop Prot. 2013:45:36-40

5. Gordon KH, Waterhouse PM. RNAi for insect-proof plants. Nat Biotechnol. 2007:25(11):1231-2.

6. Huvenne $H$, Smagghe G. Mechanisms of dsRNA uptake in insects and potential of RNAi for pest control: a review. J Insect Physiol. 2010;56(3):227-35.

7. Bucher G, Scholten J, Klingler M. Parental RNAi in Tribolium (Coleoptera). Curr Biol. 2002:12(3):R85-6.

8. Lynch JA, Desplan C. A method for parental RNA interference in the wasp Nasonia vitripennis. Nat Protoc. 2006;1(1):486-94.

9. Mito T, Ronco M, Uda T, Nakamura T, Ohuchi H, Noji S. Divergent and conserved roles of extradenticle in body segmentation and appendage formation, respectively, in the cricket Gryllus bimaculatus. Dev Biol. 2008; 313(1):67-79.

10. Whyard S, Singh AD, Wong S. Ingested double-stranded RNAs can act as species-specific insecticides. Insect Biochem Mol Biol. 2009;39(11):824-32.

11. Wynant N, Santos D, Vanden Broeck J. Biological mechanisms determining the success of RNA interference in insects. Int Rev Cell Mol Biol. 2014;312: 139-67.

12. Garbutt JS, Reynolds SE. Induction of RNA interference genes by doublestranded RNA; implications for susceptibility to RNA interference. Insect Biochem Mol Biol. 2012;42(9):621-8.

13. Yu N, Christiaens O, Liu J, Niu J, Cappelle K, Caccia S, Huvenne H, Smagghe G. Delivery of dsRNA for RNAi in insects: an overview and future directions. Insect Sci. 2013;20(1):4-14.

14. Baum JA, Bogaert T, Clinton W, Heck GR, Feldmann P, llagan O, Johnson S, Plaetinck G, Munyikwa T, Pleau M, et al. Control of coleopteran insect pests through RNA interference. Nat Biotechnol. 2007;25(11):1322-6.

15. Mao YB, Cai WJ, Wang JW, Hong GJ, Tao XY, Wang LJ, Huang YP, Chen XY. Silencing a cotton bollworm P450 monooxygenase gene by plant-mediated RNAi impairs larval tolerance of gossypol. Nat Biotechnol. 2007;25(11):1307-13.

16. Mao YB, Tao XY, Xue XY, Wang LJ, Chen XY. Cotton plants expressing CYP6AE14 double-stranded RNA show enhanced resistance to bollworms. Transgenic Res. 2011;20(3):665-73.

17. Pitino M, Coleman AD, Maffei ME, Ridout CJ, Hogenhout SA. Silencing of aphid genes by dsRNA feeding from plants. PLoS One. 2011;6(10):e25709.

18. Zha W, Peng X, Chen R, Du B, Zhu L, He G. Knockdown of midgut genes by dsRNA-transgenic plant-mediated RNA interference in the hemipteran insect Nilaparvata lugens. PLoS One. 2011;6(5):e20504.

19. Kumar P, Pandit SS, Baldwin IT. Tobacco rattle virus vector: a rapid and transient means of silencing manduca sexta genes by plant mediated RNA interference. PLoS One. 2012;7(2):e31347. 
20. Liu F, Wang XD, Zhao YY, Li YJ, Liu YC, Sun J. Silencing the HaAK gene by transgenic plant-mediated RNAi impairs larval growth of Helicoverpa armigera. Int J Biol Sci. 2015;11(1):67-74.

21. Mamta, Reddy KR, Rajam MV. Targeting chitinase gene of Helicoverpa armigera by host-induced RNA interference confers insect resistance in tobacco and tomato. Plant Mol Biol. 2015;90:281-92.

22. Jin S, Singh ND, Li L, Zhang $X$, Daniell $H$. Engineered chloroplast dsRNA silences cytochrome p450 monooxygenase, V-ATPase and chitin synthase genes in the insect gut and disrupts Helicoverpa armigera larval development and pupation. Plant Biotechnol J. 2015;13(3):435-46.

23. Kranthi KR, Russell D, Wanjari R, Kherde M, Munje S, Lavhe N, Armes N. Inseason changes in resistance to insecticides in Helicoverpa armigera (Lepidoptera: Noctuidae) in India. J Econ Entomol. 2002;95(1):134-42.

24. Storer NP, Babcock JM, Schlenz M, Meade T, Thompson GD, Bing JW, Huckaba RM. Discovery and characterization of field resistance to Bt maize: Spodoptera frugiperda (Lepidoptera: Noctuidae) in Puerto Rico. J Econ Entomol. 2010;103(4):1031-8.

25. Kumar P, Pandit SS, Steppuhn A, Baldwin IT. Natural history-driven, plantmediated RNAi-based study reveals CYP6B46's role in a nicotine-mediated antipredator herbivore defense. Proc Natl Acad Sci U S A. 2014;111(4):1245-52.

26. Poreddy S, Mitra S, Schottner M, Chandran J, Schneider B, Baldwin IT, Kumar P, Pandit SS. Detoxification of hostplant's chemical defence rather than its anti-predator co-option drives beta-glucosidase-mediated lepidopteran counteradaptation. Nat Commun. 2015;6:8525

27. Xiu WM, Zhou YZ, Dong SL. Molecular characterization and expression pattern of two pheromone-binding proteins from Spodoptera litura (Fabricius). J Chem Ecol. 2008;34(4):487-98.

28. Liao C, Heckel DG, Akhurst R. Toxicity of Bacillus thuringiensis insecticidal proteins for Helicoverpa armigera and Helicoverpa punctigera (Lepidoptera: Noctuidae), major pests of cotton. J Invertebr Pathol. 2002;80(1):55-63.

29. Fitt GP. The ecology of Heliothis species in relation to agroecosystems. Annu Rev Entomol. 1989:34:17-52.

30. Halitschke R, Schittko U, Pohnert G, Boland W, Baldwin IT. Molecular interactions between the specialist herbivore Manduca sexta (Lepidoptera, Sphingidae) and its natural host Nicotiana attenuata. III. Fatty acid-amino acid conjugates in herbivore oral secretions are necessary and sufficient for herbivore-specific plant responses. Plant Physiol. 2001;125(2):711-7.

31. Kessler A, Baldwin I. Herbivore-induced plant vaccination. Part I. The orchestration of plant defenses in nature and their fitness consequences in the wild tobacco Nicotiana attenuata. Plant J. 2004;38(4):639-49.

32. Kawahara AY, Breinholt JW, Ponce FV, Haxaire J, Xiao L, Lamarre GP, Rubinoff D, Kitching IJ. Evolution of Manduca sexta hornworms and relatives: biogeographical analysis reveals an ancestral diversification in central America. Mol Phylogenet Evol. 2013;68(3):381-6.

33. Kester KM, Barbosa P. Behavioral responses to host foodplants of two populations of the insect parasitoid Cotesia congregata (say). Oecologia. 1994:99(151):1-2.

34. Sannino L, Espinosa B, Balbiani A: Comparative morphological study on the immature stages of the Lepidoptera tobacco pests 2 larvae. Boll Lab Entomologia Agraria Filippo Silvestri 1995, 50 (0):23-91.

35. Peterson SC, Hanson FE, Warthen JD. Deterrence coding by a larval Manduca chemosensory neurone mediating rejection of a non-host plant, Canna generalis L. Physiol Entomol. 1993;18(3):285-95.

36. Bossart JL, Gage SH. Biology and seasonal occurrence of Manduca quinquemaculata and M. sexta (Lepidoptera: Sphingidae) in southwestern Michigan. Environ Entomol. 1990;19(4):1055-9.

37. Raguso RA, Willis MA. Olfactory vs. visual cues in hawkmoth attraction to night-blooming flowers. Bull Ecol Soc Am. 1997;78:166.

38. Schittko U, Preston CA, Baldwin IT. Eating the evidence? Manduca sexta larvae can not disrupt specific jasmonate induction in Nicotiana attenuata by rapid consumption. Planta. 2000;210(2):343-6

39. Kessler A, Baldwin I. Manduca quinquemaculata's optimization of intra-plant oviposition to predation, food quality, and thermal constraints. Ecology. 2002:83(8):2346-54.

40. Kessler A, Baldwin IT. Defensive function of herbivore-induced plant volatile emissions in nature. Science. 2001;291(5511):2141-4.

41. Younis A, Siddique MI, Kim CK, Lim KB. RNA interference (RNAi) induced gene silencing: a promising approach of hi-tech plant breeding. Int J Biol Sci. 2014;10(10):1150-8.

42. Nandety RS, Kuo YW, Nouri S, Falk BW. Emerging strategies for RNA interference (RNAi) applications in insects. Bioengineered. 2015;6(1):8-19.
43. Mutti NS, Park Y, Reese JC, Reeck GR. RNAi knockdown of a salivary transcript leading to lethality in the pea aphid, Acyrthosiphon pisum. J Insect Sci. 2006;6:1-7.

44. Tian H, Peng H, Yao Q, Chen H, Xie Q, Tang B, Zhang W. Developmental control of a lepidopteran pest Spodoptera Exigua by ingestion of bacteria expressing dsRNA of a non-midgut gene. PLoS One. 2009;4(7):e6225.

45. Arimatsu Y, Kotani E, Sugimura Y, Furusawa T. Molecular characterization of a cDNA encoding extracellular dsRNase and its expression in the silkworm, Bombyx Mori. Insect Biochem Mol Biol. 2007;37(2):176-83.

46. Levin DM, Breuer LN, Zhuang S, Anderson SA, Nardi JB, Kanost MR. A hemocyte-specific integrin required for hemocytic encapsulation in the tobacco hornworm, Manduca sexta. Insect Biochem Mol Biol. 2005;35(5):369-80.

47. Eleftherianos I, Felfoldi G, ffrench-Constant RH, Reynolds SE. Induced nitric oxide synthesis in the gut of Manduca sexta protects against oral infection by the bacterial pathogen Photorhabdus luminescens. Insect Mol Biol. 2009; 18(4):507-16.

48. Howlett N, Dauber KL, Shukla A, Morton B, Glendinning Jl, Brent E, Gleason C, Islam F, Izquierdo D, Sanghavi S, et al. Identification of chemosensory receptor genes in Manduca sexta and knockdown by RNA interference. BMC Genomics. 2012;13:211.

49. Garbutt JS, Belles X, Richards EH, Reynolds SE. Persistence of doublestranded RNA in insect hemolymph as a potential determiner of RNA interference success: evidence from Manduca sexta and Blattella germanica. $J$ Insect Physiol. 2013;59(2):171-8.

50. Mamta B, Rajam MV. RNAi technology: a new platform for crop pest control. Physiol Mol Biol Plants. 2017;

51. Kamthan A, Chaudhuri A, Kamthan M, Datta A. Small RNAs in plants: recent development and application for crop improvement. Front Plant Sci. 2015;6:208.

52. Schwachtje J, Kutschbach S, Baldwin IT. Reverse genetics in ecological research. PLoS One. 2008;3(2):e1543.

53. Steppuhn A, Gase K, Krock B, Halitschke R, Baldwin IT. Nicotine's defensive function in nature. PLOS Biol. 2004;2(8):E217

54. Heiling S, Schuman MC, Schoettner M, Mukerjee P, Berger B, Schneider B, Jassbi AR, Baldwin IT. Jasmonate and ppHsystemin regulate key malonylation steps in the biosynthesis of 17-hydroxygeranyllinalool diterpene glycosides, an abundant and effective direct defense against herbivores in Nicotiana attenuata. Plant Cell. 2010:22(1):273-92.

55. Krügel T, Lim M, Gase K, Halitschke R, Baldwin IT. Agrobacterium-mediated transformation of Nicotiana attenuata, a model ecological expression system. Chemoecology. 2002;12(4):177-83.

56. Bustin SA, Beaulieu J-F, Huggett J, Jaggi R, Kibenge FS, Olsvik PA, Penning LC, Toegel S. MIQE précis: practical implementation of minimum standard guidelines for fluorescence-based quantitative real-time PCR experiments. BMC Mol Biol. 2010;11(1):74.

\section{Submit your next manuscript to BioMed Central and we will help you at every step:}

- We accept pre-submission inquiries

- Our selector tool helps you to find the most relevant journal

- We provide round the clock customer support

- Convenient online submission

- Thorough peer review

- Inclusion in PubMed and all major indexing services

- Maximum visibility for your research

Submit your manuscript at www.biomedcentral.com/submit
C) Biomed Central 